\title{
UNA INSCRIPCIÓN GRIEGA ARCAICA HALLADA EN EL CABEZO DE SAN PEDRO (HUELVA)
}

\section{AN ARCHAIC GREEK INSCRIPTION FOUND AT CABEZA DE SAN PEDRO (HUELVA)}

\author{
M. GARCÍA FERNÁNDEZ* \\ A. J. DOMÍNGUEZ MONEDERO** \\ F. GONZÁLEZ DE CANALES*** \\ L. SERRANO PICHARDO*** \\ J. LLOMPART GÓMEZ***
}

Resumen: El hallazgo de una inscripción griega incisa sobre un cuenco de cerámica gris orientalizante atestigua, una vez más, la presencia en Huelva de gente que sabía escribir en griego. En la misma intervención arqueológica fueron documentados dos vasos griegos arcaicos que abren una nueva perspectiva a la ocupación del Cabezo de San Pedro durante el espacio temporal de presencia efectiva griega en el hábitat, cuando era conocido como Tarteso.

Palabras claves: Tarteso, Cabezo de San Pedro, Huelva, Inscripción griega arcaica, Nike.

\section{INTRODUCCIÓN}

El área donde se produjo el hallazgo (fig. 1) está sometida a dos figuras de protección: la Declaración de Bien de Interés Cultural con la categoría de Monumento de la Iglesia de San Pedro (Decreto 691/1999, de 16 de marzo, BOJA núm. 52, de 6 de mayo de 1999) y la Inscripción Específica en el Catálogo General del Patrimonio Histórico Andaluz de la Zona Arqueológica

\footnotetext{
* IntAR-Huelva, Intervenciones Arqueológicas.

** Departamento de Historia Antigua, Universidad Autónoma de Madrid

*** Centro de Estudios Fenicios y Púnicos (UCM)
}

\begin{abstract}
We are presenting a Greek inscription carved in an orientalizing grey ceramic bowl which once again bears witness of the presence in Huelva of people who knew how to write in Greek. Within the same archaeological undertaking two Greek archaic vases were documented which open a new perspective to the occupation of the Cabezo de San Pedro site during the time of effective Greek presence in the habitat, when it was called Tartessus.
\end{abstract}

Key words: Tartessus, Cabezo de San Pedro, Huelva, Archaic Greek Inscription, Nike.

de Huelva (Orden de 14 de mayo de 2001, BOJA núm. 75 , de 3 de julio de 2001).

Transcurridos treinta años desde la última intervención arqueológica en el Cabezo de San Pedro, en el verano de 2007 se inició una nueva actuación determinada por la urbanización prevista de unos solares en la Calle Aragón, a pie del cabezo. A tal fin y en prevención de desprendimientos no controlados, como el ocurrido en 1956 que ocasionó un elevado número de heridos y muertos, se proyectó la ejecución de taludes con pendientes calculadas para dotar de estabilidad a la estructura geológica de la ladera suroeste del cabezo (fig. 2). De este modo, tuvieron lugar una serie de actuaciones encaminadas a la estabilización, consolidación y drenaje de la zona. 


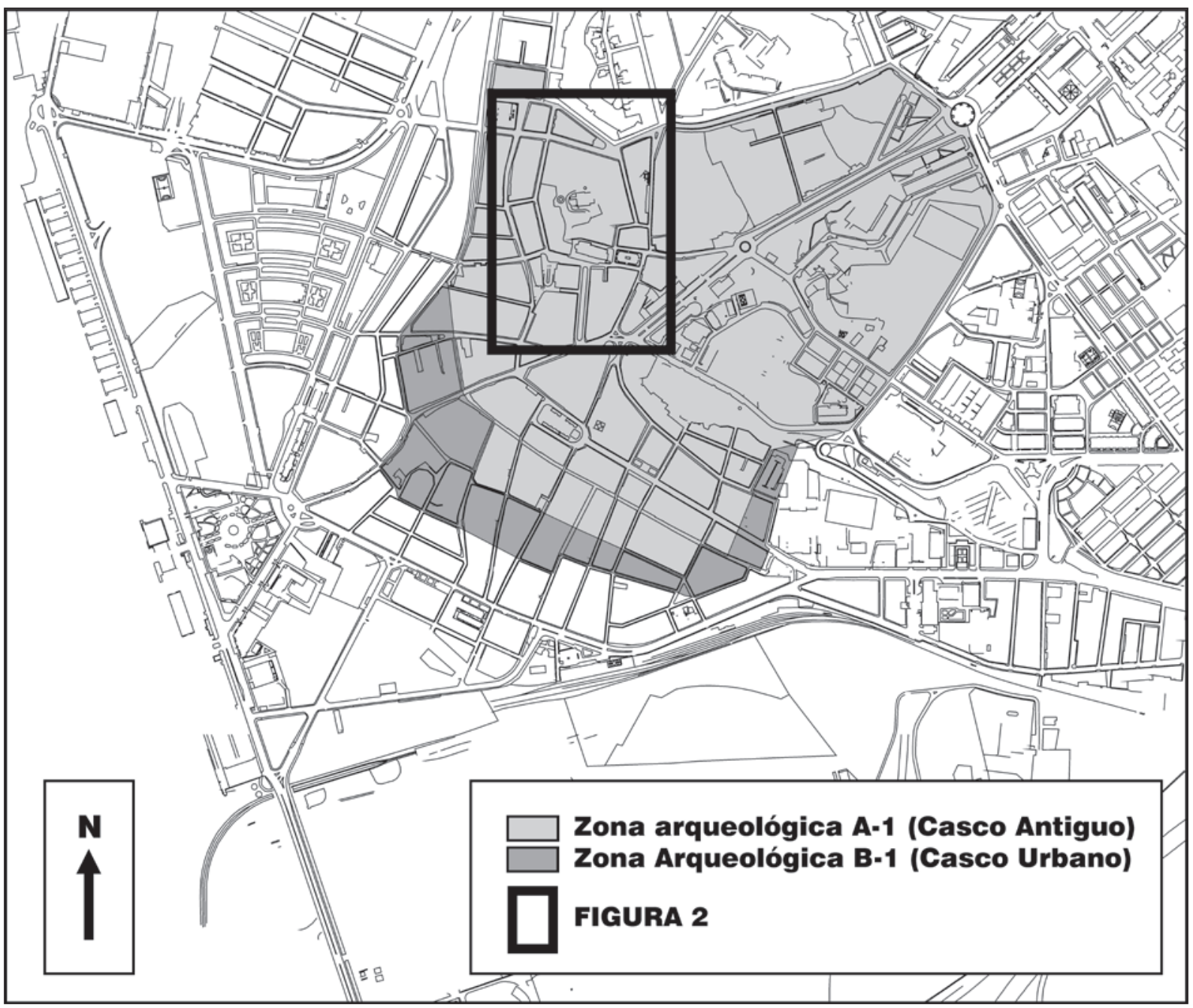

Figura 1.

Con anterioridad a la ejecución del proyecto y acorde con las cautelas dictadas por la Delegación Provincial de Cultura, durante el proceso manual de limpieza del perfil fueron documentados dos elementos estructurales arqueológicos visibles en la ladera, denominados "muro" y "pozo". Además se procedió a:

1. Definir la línea de contacto entre las arenas terciarias constitutivas del cabezo y los niveles antrópicos.

2. Determinar la secuencia histórica (crono-cultural) del solar en atención a las directrices y conocimiento de la Zona Arqueológica de Huelva.

3. Documentar las dinámicas deposicionales y postdeposicionales, con especial atención a los niveles protohistóricos y su alteración por fosas de épocas posteriores.
4. Posicionar mediante coordenadas UTM y cota absoluta las estructuras arqueológicas y los niveles de ocupación documentados.

5. Crear una de red de datos exclusivamente arqueológicos: 280 puntos georeferenciados.

6. Recuperar los materiales arqueológicos situados en el perfil: 564 fragmentos cerámicos descritos e inventariados, entre los que cobran especial relevancia dos vasos griegos arcaicos de Grecia del Este y un cuenco local de cerámica gris con la inscripción griega que presentamos.

Para ubicar el posicionamiento de estos elementos arqueológicos con exactitud y determinar los cambios producidos en la topografía del cabezo desde la realización del parcelario de 1997 , fue realizado un 


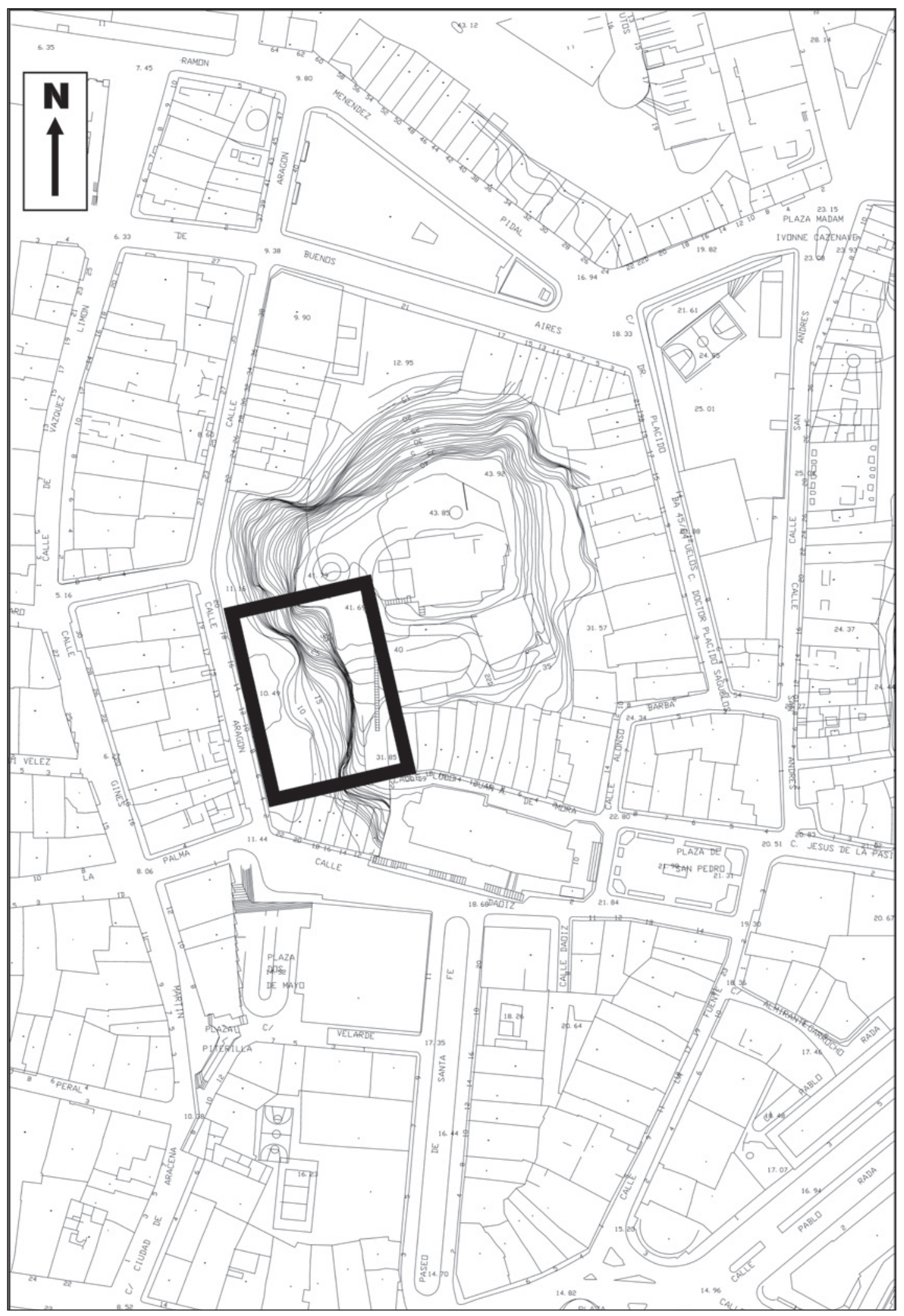

Figura 2.

ISSN: 1133-4525 ISSN-e: 2255-3924 

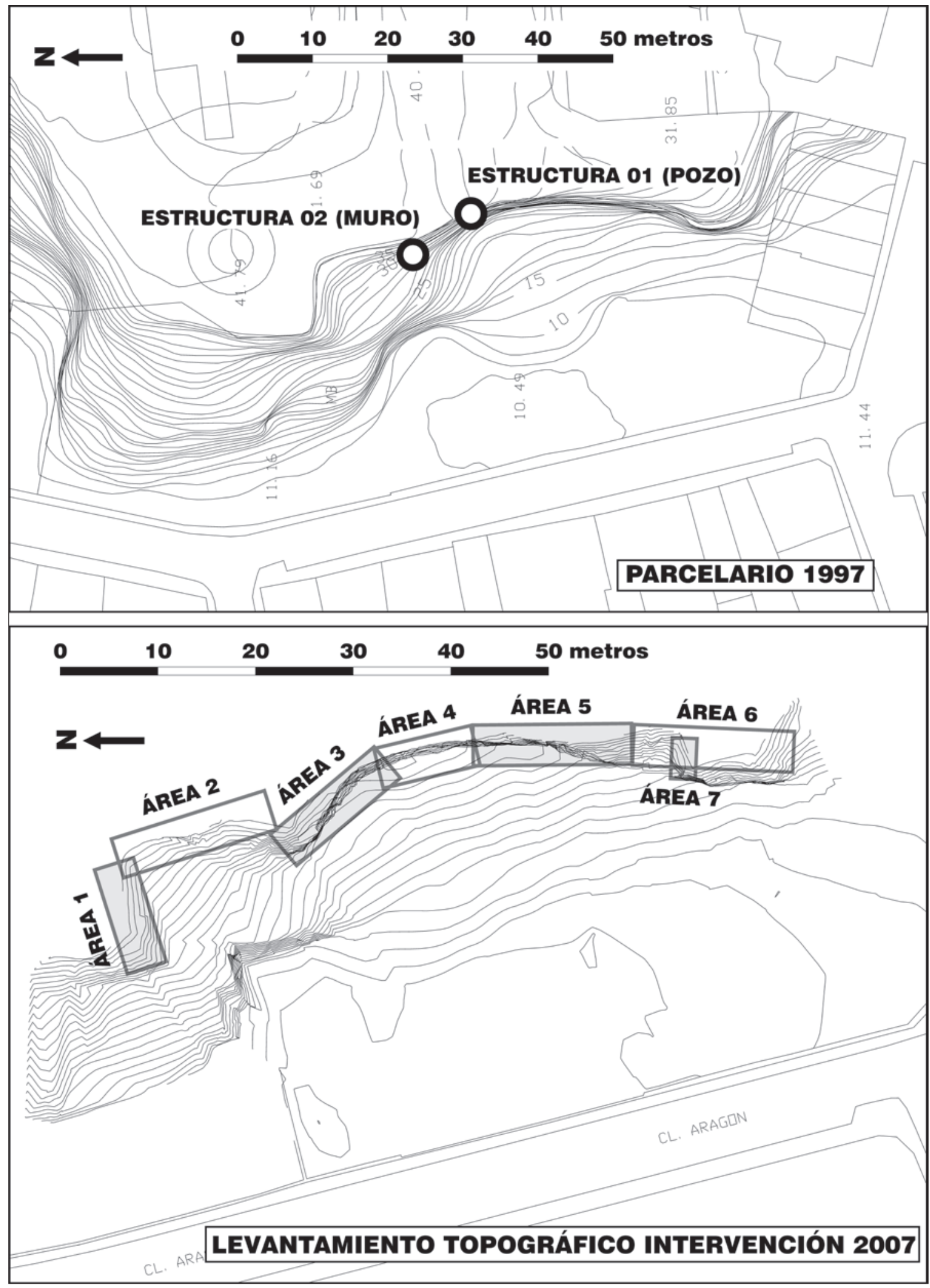

Figura 3. 


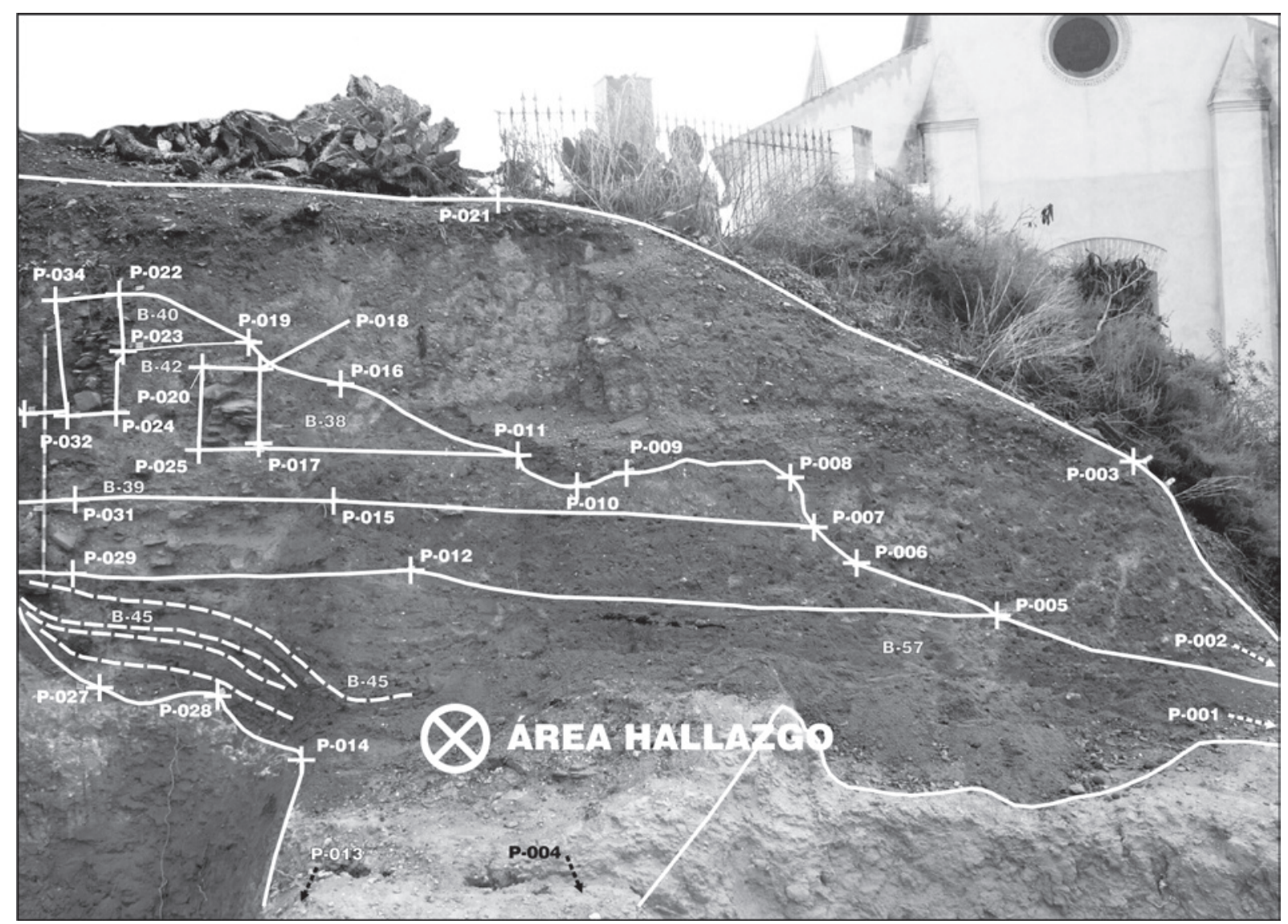

Figura 4.

levantamiento topográfico sobre el que se establecieron las áreas de actuación arqueológica (fig. 3).

\section{CONTEXTUALIZACIÓN DEL HALLAZGO}

El fragmento que portaba la inscripción (LSP 526) fue hallado durante la limpieza del perfil correspondiente al Área de Intervención 7 (fig. 4) asociado a la estructura muraria denominada Muro E (MUE). Esta estructura, delimitada por los puntos topográfi$\cos 147$ a 152, apoyaba directamente sobre las arenas terciarias del cabezo, por tanto sin niveles antrópicos subyacentes.

En el mismo contexto fueron exhumados dos fragmentos (LSP 192 y LSP 525) correspondientes a un vaso de Grecia del Este (fig. 5) de la primera mitad del siglo VI a.C. Junto a estos elementos se documentaron otros materiales, tanto cerámicos (vajillas fenicia e indígena), como metalúrgicos (escorias de sílice libre).
El citado vaso de Grecia del Este y otro de igual filiación y similar cronología hallado en la misma intervención constituyen una novedad en el Cabezo de San Pedro, pues las cerámicas griegas conocidas con anterioridad habían sido asignadas con preferencia al siglo IV a.C. (Olmos 1978: 386; Amo y Belén 1981: 128), un momento histórico posterior que las adscribía al ámbito del comercio cartaginés. Por el contrario, las zonas bajas del hábitat habían proporcionado frecuentes cerámicas griegas arcaicas, llegando a ser muy numerosas en algunos solares.

\section{DESCRIPCIÓN DEL SOPORTE}

La epigrafía fue realizada sobre un cuenco gris a torno de tendencia hemisférica y superficies bruñidas del que se conserva un fragmento que comprende parte del borde y galbo. El borde aparece levemente engrosado por el interior, mientras que el exterior, diferenciado del galbo por un tenue estrangulamiento, ofrece 


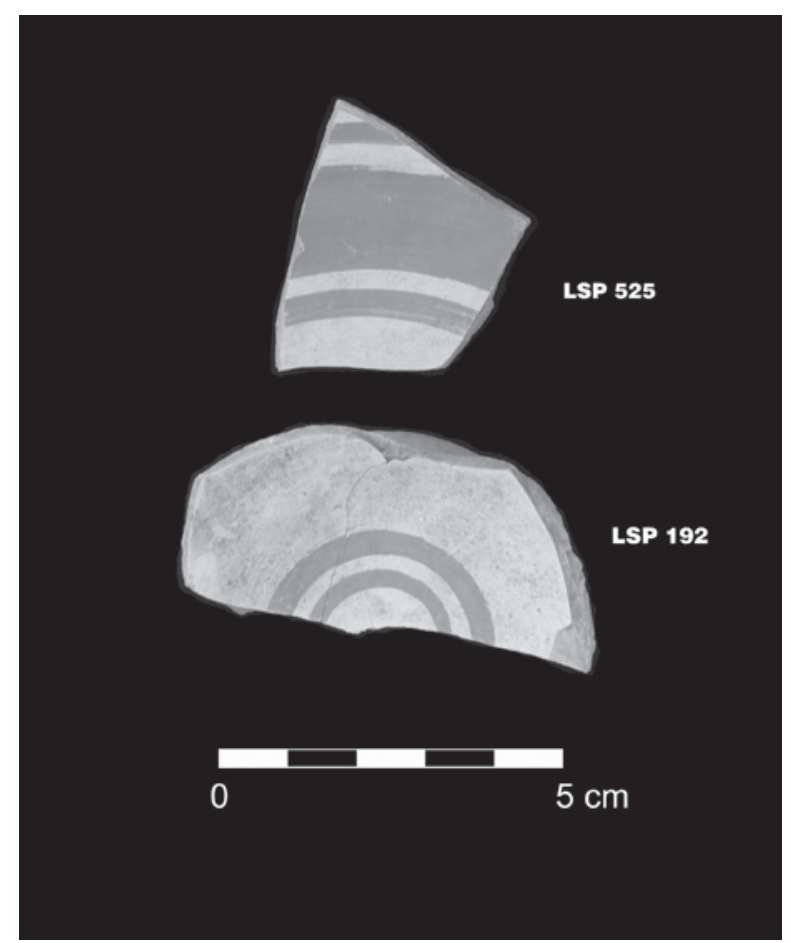

Figura 5.

un perfil redondeado (fig. 6). La pasta es de color gris (10YR6/1 de la carta de Munsell), dura, homogénea y con desgrasantes finos y muy finos que incluyen escasa moscovita. La inscripción, mediante incisión postcochura, se localiza hacia la mitad del galbo, justo en la línea de fractura antigua (fig. 7).
Dentro de las cerámicas grises orientalizantes, el referente formal más cercano lo proporciona el subtipo 1E1 de Lorrio (1988-1989: 290 y fig. 6.1E1), aunque también podría aproximarse a la forma 20B de Caro (1989: 168 y 172-173) y al tipo IC1 de Mancebo (1994: 353 y fig. 1).

Es criterio generalizado que las cerámicas grises orientalizantes, relacionadas en origen con la presencia fenicia, muestran una amplia dispersión en el suroeste de la Península Ibérica y un dilatado marco cronológico a partir de la segunda mitad del siglo VIII a.C.

\section{LECTURA E INTERPRETACIÓN PALEOGRÁFICA \\ (Adolfo J. Domínguez Monedero)}

La dirección del texto es, sin duda, de izquierda a derecha como muestran los trazados de letras significativas, como la kappa y, sobre todo, la epsilon. El uso de la letra $\mathrm{H}$ entre consonantes descarta que se trate de un diacrítico que marque una aspiración, por lo que no cabe duda de que se trata de la letra eta, que denota la e larga frecuente en los dialectos greco-orientales. Para la grafía de las letras encontramos paralelos interesantes en inscripciones de esa misma área greco-oriental; caracteres muy semejantes a los de nuestra inscripción aparecen, por ejemplo, en una inscripción en piedra de Quíos, bustrofédica, que se data a mediados del s. VI a.C. (Jeffery 1990: 343.41), de carácter monumental. En un soporte semejante, esto es, cerámica,

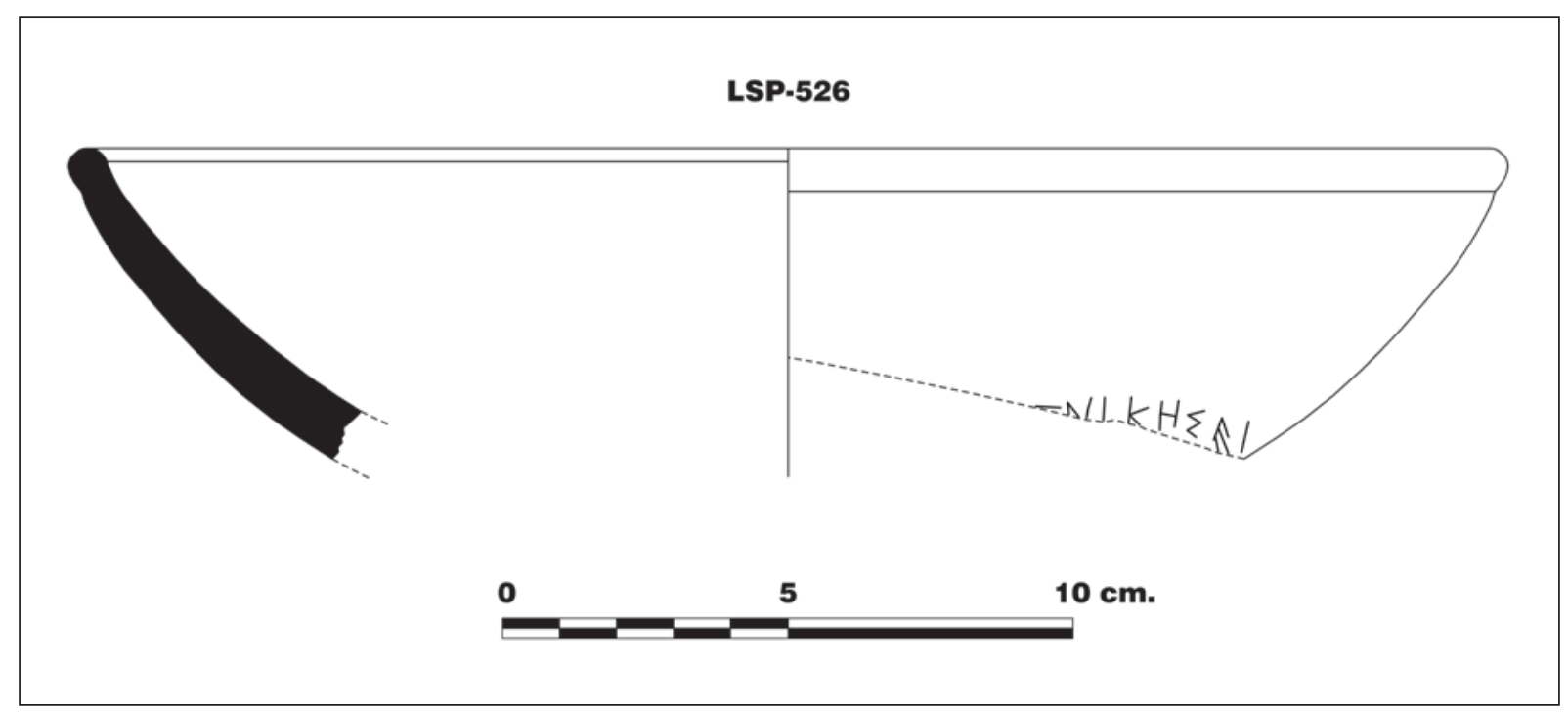

Figura 6. 


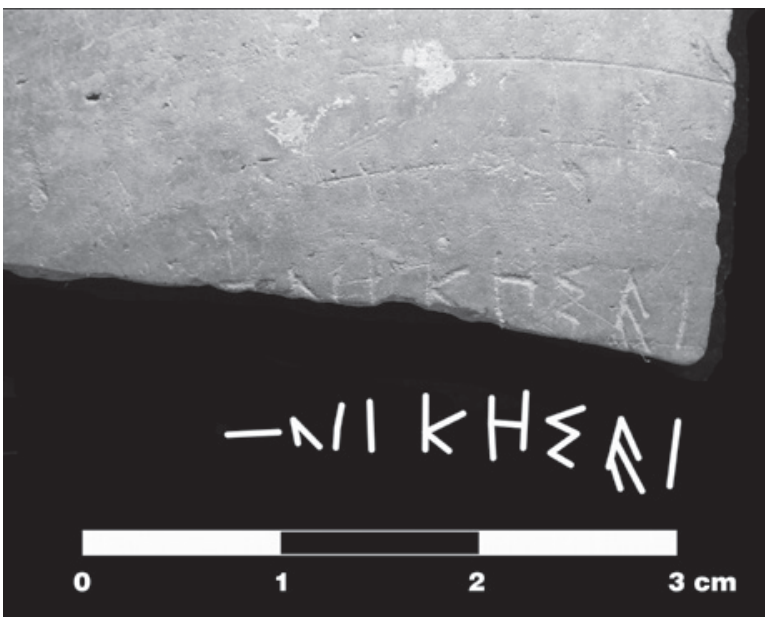

Figura 7.

encontramos gran número de paralelos en los graffiti hallados en Náucratis en las campañas de Petrie y de Gardner, que se datan, en su mayoría, a lo largo del s. VI a.C. (Petrie 1886, especialmente láms. XXXIIXXXIII y lám. XXXVA con el resumen de los distintos tipos de letra presentes; Gardner 1888, especialmente lám. XXI)

Una vez determinado el alfabeto podemos pasar a la lectura; las letras están bien grabadas, con trazos seguros y cuidados y, salvo la primera letra, la lectura no plantea demasiadas dificultades. De la primera letra (si es que es tal) sólo se conserva un trazo horizontal sin que se perciba en la fotografía que me ha sido facilitada si algún otro trazo continúa, en alguna dirección, al horizontal. Teniendo en cuenta el tipo de alfabeto sugerido (greco-oriental) las posibilidades son varias: gamma, zeta, xi, pi y tau. La ausencia de trazos a su izquierda hace difícil sugerir a qué palabra pertenece.

El resto de las letras tiene una lectura relativamente

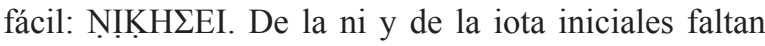
casi dos terceras partes, mientras que de la kappa falta sólo una pequeña porción de su parte inferior. Las otras letras se encuentran completas.

En cuanto a la interpretación, creemos factibles dos. En primer lugar, que se trate de una palabra; vıки́бєı tiene perfecto sentido en griego. Puede ser la tercera persona del singular del futuro de indicativo del verbo

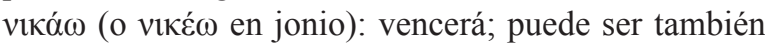
la tercera persona del singular del aoristo de subjuntivo del mismo verbo: que (él) venza. Por fin, puede ser la segunda persona del singular del futuro de indicativo en voz media del mismo verbo: me vencerás. Por supuesto, tampoco podemos descartar que la palabra no esté completa, lo que sugeriría diversas posibilidades:

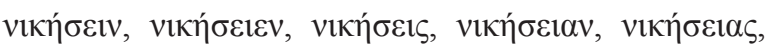

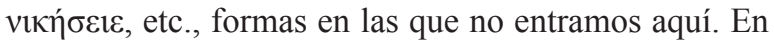
cualquiera de estos casos, en especial en los primeros que hemos mencionado, podríamos ver una imprecación eventualmente dentro de un ambiente convivial en el que, como es sabido, las competiciones de diverso tipo (canto, danza, etc.) no son infrecuentes (Domínguez Monedero 1995). Sobre las intensas relaciones entre el komos y conceptos como victoria, vid. las atinadas observaciones de Thompson (1920: 8-13): "Nike es el resultado de un agon y es celebrada en un komos". Representaciones de comastas, o individuos que parti-

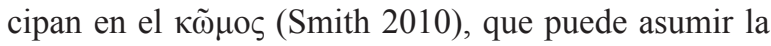
forma de esa procesión burlesca de borrachos que celebran diversas victorias (Bron 2002; 2007) y que, de algún modo, remeda las procesiones de los vencedores en competiciones atléticas (Pind., Pyth., V, 22) son bien conocidas en Huelva, con algunos ejemplares publicados de las llamadas "copas de Comastas" (Olmos 1987; González de Canales y otros 1991). Que en un contexto de banquete alguien que supiese escribir griego hubiese escrito alguna imprecación del tipo: ¡vencerás! o ¡que venzas! no resultaría extraño, pues este uso simposiástico de la escritura parece atestiguarse desde los ejemplos más antiguos de la utilización de la escritura en Grecia. Por ejemplo, en la llamada "copa de Néstor" de Pitecusas, cuya inscripción algunos autores, como $\mathrm{Mu}$ rray (1994), han sugerido que pudo realizarse durante algún agon simposiasta. Si esta es la interpretación correcta, no deja de ser curioso observar cómo esta costumbre de la escritura simposiástica se efectúa no sobre un vaso griego, de los que tan gran número de ejemplares ha aparecido en Huelva, sino en un vaso de tipología y manufactura, en apariencia, no griega.

Una segunda línea de interpretación viene dada por la posibilidad de que no tengamos una forma verbal sino, al menos, dos palabras, una de ellas incompleta. En este caso podríamos leer Níkn si[ $\mu$ í́], "soy de Niké". Este tipo de inscripción dedicatoria donde es el propio vaso el que habla e indica (en genitivo) qué divinidad es su propietario es bastante frecuente en las fórmulas dedicatorias griegas, con abundantes paralelos. Por ejemplo, en el santuario de Gravisca, donde también hay una fuerte presencia greco-oriental durante buena parte del s. VI a.C., éste es uno de los dos tipos mayoritarios de inscripciones votivas (Johnston y Pandolfini 2000: 23-24).

Nike es una figura enigmática, hija de Estigia, hija a su vez de Océano, y de Palante (Hes., Theog., 383384) y que vive con Zeus por todos los siglos (Ibid., 399-403). De hecho en la estatua de Zeus del santuario 
de Olimpia, el padre de los dioses sostiene en su mano derecha una Nike y varias figuras de Nike se representan a los pies de su trono (Paus., V, 11, 1-2); asimismo, junto al altar de Zeus en el mismo santuario hay un altar conjunto de Zeus Catarsio (el purificador) y de Nike (Paus., V, 14, 8). En Homero no aparece como personificación sino como algo aleatorio y fugaz cuando se consigue y efímero cuando la otorgan los dioses (Leclerc 1997). Quizá haya permanecido más como una abstracción que como una divinidad con culto propio hasta, al menos, el siglo VI a.C., momento en el que empieza a aparecer en el arte y en la literatura, adquiriendo poco a poco un papel cada vez más importante (Hamdorf 1964: 58-59). Sin duda es en Atenas donde, gracias a su asociación con Atenea, alcanzará una mayor relevancia (Daly 1953; Mark 1979). Según algunos autores Nike parece haber sido en un primer momento una divinidad que proporcionaba la victoria en competiciones gimnásticas y musicales (Sikes 1985), aunque quizá su fusión con Atenea la haya convertido en una divinidad que concede el éxito en la guerra (Mark 1993: 96; otros autores, más antiguos, consideran por el contrario que, a partir del siglo V a.C., se habría producido la separación de Atenea y Nike previamente identificadas, vid. al respecto Baudrillart 1894: 6-19).

En la iconografía, tanto en cerámicas como en monedas, Nike empieza a estar presente ya a partir del siglo VI a.C. (Knapp 1876; Imhoof-Blumer 1871; Isler-Kerényi 1969) y conocerá un amplio desarrollo durante el V, en especial en Atenas (Thöne 1999). El siglo VI a.C., pues, parece haber sido un momento importante para la definición de la personalidad de Nike; a esa época pertenece el escultor Arquermo que habría sido el primero en representar a esta figura con alas hacia el 560 a.C. (Schol. Ar. Av., 574), contribuyendo así de forma importante al desarrollo de su iconografía. Parece que es este mismo escultor de Quíos quien, junto a su padre, dedica en el santuario de Artemis en Delos un monumento a Nike (según alguna de las lecturas restituidas de su base) coronado con una figura de Nike; el escultor y sus hijos, también escultores, se trasladarían a Atenas donde introducirían esa nueva creación (el tema ha generado gran cantidad de literatura; mencionaré, para la inscripción, Jeffery 1990: 305.30 y Scherrer 1983; para la escultura, puestas al día en Sheedy 1985 y Ridgway 1986). Quizá del éxito de Nike en Atenas pueda dar cuenta un monumento dedicado por el polemarco Calímaco en la acrópolis de Atenas en el mismo año de la batalla de Maratón (490 a.C.); este personaje, que dirigió el ejército ateniense en dicha batalla (Hdt., VI, 109) parece haber dedicado, antes de su muerte en la misma, ese monumento en el que se alude a una victoria (algu-

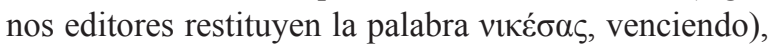
en las Panateneas de ese año en virtud de la cual dedica un monumento a Atenea coronado con una Nike; pero, mientras tanto, se ha producido la batalla de Maratón, en la que la valentía de Calímaco conduce a la victoria, por lo que la Nike, apropiada para la victoria atlética, lo será también para la victoria militar (Harrison 1971).

Sea cual sea la interpretación correcta de las dos que aquí proponemos para la inscripción de Huelva, ambas encajan bien, aunque de distinta forma, con el ambiente empórico onubense. Si se trata de una forma verbal sería un testimonio de la realización de prácticas simposiastas en las que se hallarían involucrados griegos y donde una inscripción augurando la victoria en un vaso, dentro de la celebración de un banquete y un komos, tendría pleno sentido; la presencia de vasos griegos con representaciones de comastas hallados en diversos lugares de la ciudad, llevados allí por griegos, muestran el conocimiento y eventual práctica de tales actividades.

$\mathrm{Si}$, por el contrario, se trata de una dedicatoria a Nike, indicaría la popularización de ese culto entre los visitantes o residentes griegos en el emporio onubense; el hecho de que sea en ambiente greco-oriental (en concreto quiota) donde tenemos atestiguado un cierto interés por esa figura en los momentos en los que la misma empieza a dotarse de una personalidad propia iría también bien con el ambiente griego de Huelva, donde la presencia de individuos de la Grecia del Este, foceos sobre todo pero también gentes de otras procedencias dentro de esa región no puede descartarse (Domínguez Monedero 2000). Producciones quiotas han sido halladas en Huelva (Cabrera Bonet 1990: 60-61) y las relaciones entre Focea y Quíos, antes de la presencia persa, parecen haber sido buenas ( $c f$. Hdt., I, 165).

Cabe también la posibilidad de que, más que a la Nike griega, la dedicatoria pueda estar refiriéndose a alguna divinidad local que presentase alguna semejanza, física o conceptual, que la hiciese asimilable por los griegos a su idea de Nike. Podría sugerirse, por ejemplo, alguna divinidad alada bien de tradición indígena $\mathrm{o}$, incluso, fenicia donde la presencia de representaciones divinas aladas no es infrecuente. La presencia en Huelva de dedicatorias en griego a divinidades locales está bien atestiguada (Fernández Jurado y Olmos 1985; Almagro Gorbea 2002). Incluso, su parentesco en el mito griego con Océano (Plácido Suárez 2008; vid. también las implicaciones del mito de Estigia y Nike desde la perspectiva de la psicología jungiana en von Franz 1985), de quien Nike sería su nieta, no desentonaría con 


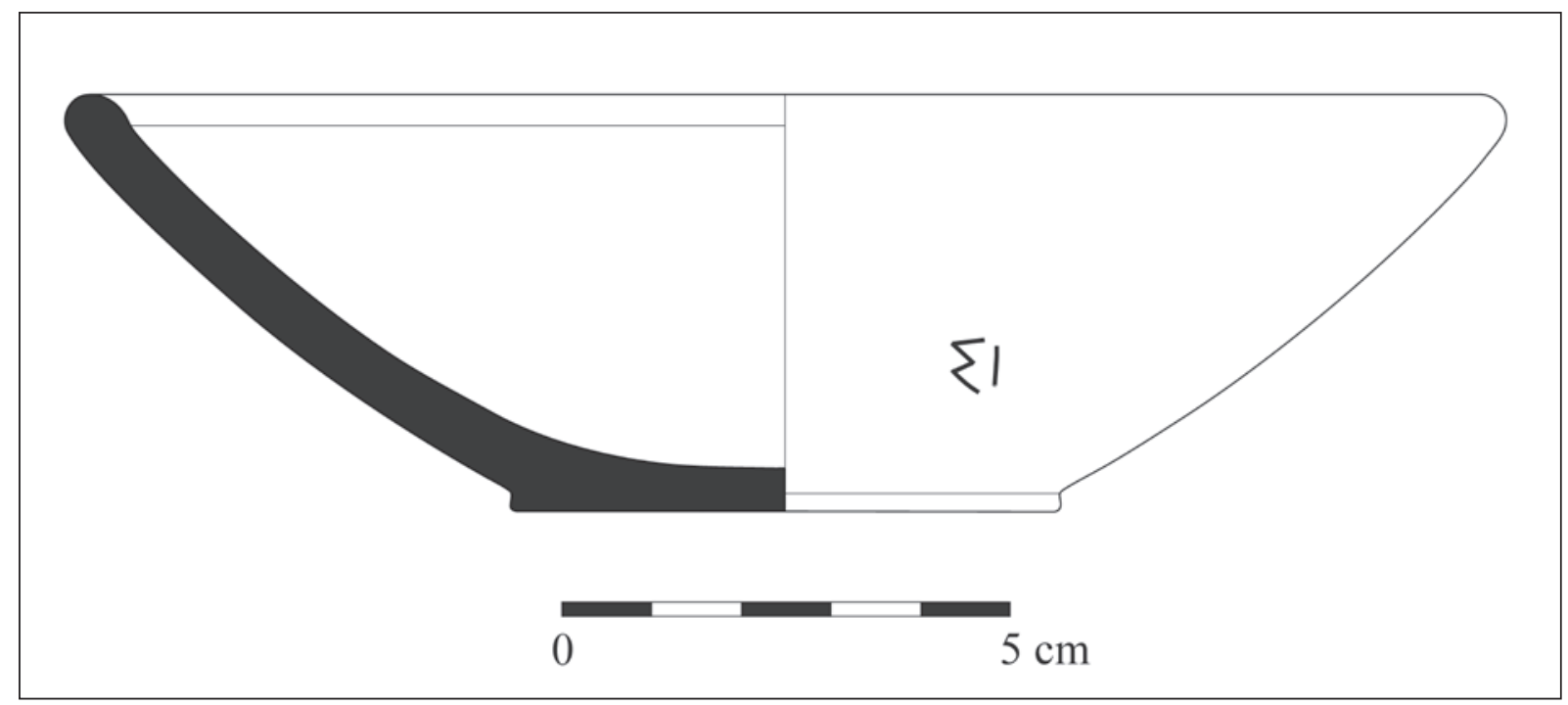

Figura 8.

una dedicatoria a Nike en ambiente onubense, situado en los extremos del mundo para los antiguos.

\section{COMENTARIOS EN TORNO AL SOPORTE Y A OTRAS INSCRIPCIONES GRIEGAS DE HUELVA}

Uno de los aspectos más interesantes de la inscripción lo constituye el soporte sobre el que asienta, pues tratándose de un vaso cerámico de producción local asegura la presencia en Huelva de alguien que sabía escribir griego. El mismo hecho es atestiguado en otras dos inscripciones griegas arcaicas procedentes del centro histórico de la ciudad, también realizadas por incisión postcochura sobre cuencos grises orientalizantes. La primera (fig. 8), limitada a dos únicas letras, sigma e iota, comunes a buen número de escrituras griegas arcaicas, incluyendo la jonia, tenía como soporte un cuenco técnicamente similar al actual (fig. 9) (González de Canales y Serrano 1995: 10-11; González de Canales y otros 2000: 230, fig. 2.5 y láms. 5A y 5B). La segunda fue interpretada como una dedicatoria a la diosa del hogar Hi/estia (Llompart y otros 2010).

Conocemos otras dos inscripciones griegas arcaicas incisas postcochura, plausiblemente realizadas en Huelva, pero cuyos soportes estaban constituidos por cerámicas griegas importadas del siglo VI a.C. En una, sobre un cuenco, quizás milesio, se lee niethoi, interpretado como un antropónimo local (Fernández Jurado y Olmos 1985: 110-111) y, alternativamente, como un teónimo en relación con Netos, divinidad celta solar y de la guerra (Almagro-Gorbea 2002: 62). La segunda, sobre una copa jonia, resultó ilegible por el deficiente estado de conservación (Fernández Jurado 1984: 32-33 y fig. 11.21). Queda al margen de esta recopilación un dipinto sobre una olpe ática decorada por Clitias, en la que se lee el nombre de la diosa Atenea (Olmos y Cabrera 1980).

Recientes excavaciones en el centro histórico de Huelva, aún inéditas, continúan aportando importantes datos adicionales sobre la conexión jonia en época arcaica.

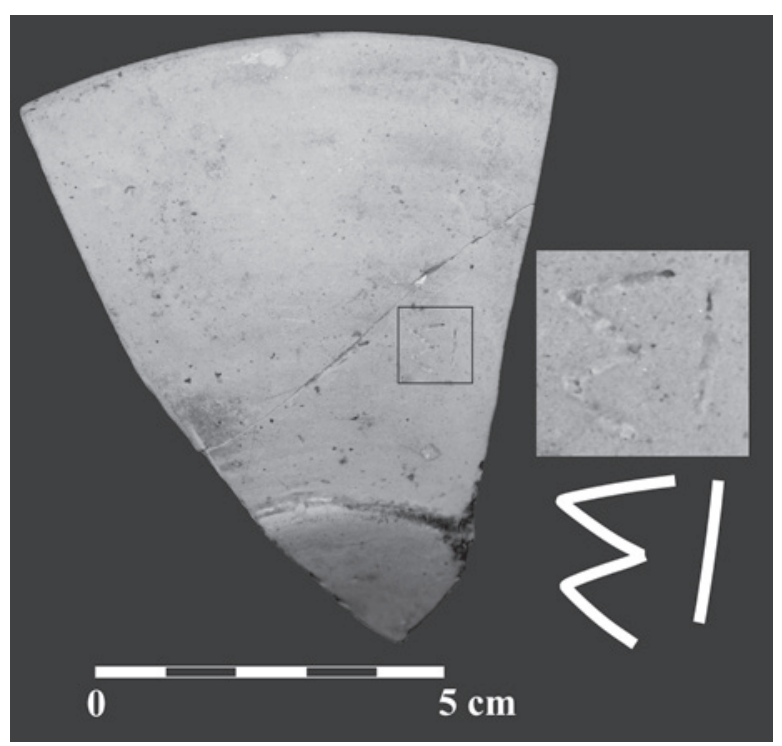

Figura 9. 


\section{BIBLIOGRAFÍA}

ALMAGRO-GORBEA, M. (2002): "Una probable divinidad tartésica identificada: Niethos/Netos", $\mathrm{Pa}$ laeohispanica 2: 37-70.

AMO DEL, M. y BELÉN, M. (1981): "Estudio de un corte estratigráfico en el Cabezo de San Pedro", Huelva Arqueológica 5: 57-148.

BAUDRILLART, A. (1894): Les divinités de la Victoire en Grèce et en Italie d'après les textes et les monuments figurés, Bibliothèque des Ecoles françaises d'Athènes et de Rome 68. Paris.

BRON, C. (2002): "Le comos dans tous ses états", Pallas 60: 269-274.

BRON, C. (2007): "Fêter la victoire”, Pallas 75: 189-195.

CABRERA BONET, P. (1990): "El comercio foceo en Huelva: cronología y fisonomía”, Huelva Arqueológica 10-11/1988-1989 (3): 41-100.

CARO BELLIDO, A. (1989): Cerámica gris a torno tartesia. Cádiz, Servicio de publicaciones de la Universidad de Cádiz.

DALY, L. W. (1953): "Nike and Athena Nike", en G. E. Mylonas y D. Raymond (eds.), Studies presented to D. M. Robinson, II: 1124-1128. Washington University, Saint-Louis.

DOMÍNGUEZ MONEDERO, A. J. (1995): "Del simposio griego a los bárbaros bebedores: El vino en Iberia y su imagen en los autores antiguos", en S. Celestino (ed.), Arqueología del Vino. Los orígenes del vino en Occidente: 21-72. Consejo Regulador de las D. O. Jerez y Manzanilla, Jerez de la Frontera.

DOMÍNGUEZ MONEDERO, A. J. (2000): "Phocaeans and other Ionians in Western Mediterranean", en F. Krinzinger (ed.), Die Ägäis und das Westliche Mittelmeer. Beziehungen und Wechselwirkungen 8. bis 5. Jh. v.Chr: 507-513. Österreichischen Akademie der Wissenschaften, Wien.

FERNÁNDEZ JURADO, J. (1984): La presencia griega arcaica en Huelva. Monografías Arqueológicas. Colección Excavaciones en Huelva 1/1984. Diputación Provincial, Huelva.

FERNÁNDEZ JURADO, J. y OLMOS, R. (1985): "Una inscripción jonia arcaica en Huelva", Lucentum 4: 107-113.

GARDNER, E. A. (1888): Naukratis. Part II. 1886. Trübner, London.

GARCÍA FERNÁNDEZ, M. (2007): Memoria Definitiva de la Intervención Arqueológica Preventiva: Labores de Estabilización, Consolidación y Drenaje de Ladera en Unidad de Ejecución del P.E.R.I. Cabezo de San Pedro. Huelva.
GONZÁLEZ DE CANALES, F. y SERRANO PICHARDO, L. (1995): "Consideraciones en torno al Tarteso griego y al Tarsis de Salomón con motivos de unos grafitos hallados en Huelva", Revista de Arqueología 175: 8-17.

GONZÁLEZ DE CANALES, F.; SERRANO, L.; GARRIDO, J. P. y ORTEGA, J. (1991): "Nuevos comastas en Tarteso", Revista de Arqueología 120: 14-17.

GONZÁLEZ DE CANALES, F., SERRANO PICHARDO, L. y GARRIDO ROIZ, J. P. (2000): "Nuevas inscripciones fenicias en Tarteso: su contexto histórico", en IV Congreso Internacional de Estudios Fenicios y Púnicos (Cádiz, 2-6 de Octubre de 1995), I: 227-238. Servicio de Publicaciones de la Universidad de Cádiz, Cádiz.

HAMDORF, F. W. (1964): Griechische Kultpersonifikationen der vorhellenistischen Zeit. Philipp von Zabern, Mainz.

HARRISON, E. B. (1971): "The victory of Kallimachos", Greek, Roman and Byzantine Studies 12: 5-24.

IMHOOF-BLUMER, F. (1871): "Die Flügelgestalten der Athena un Nike auf Münzen", Numismatische Zeitschrift 3: 1-50.

ISLER-KERÉNYI, C. (1969): Nike. Der Typus der laufenden Flügelfrau in archaischer Zeit. Eugen Rentsch, Erlenbach-Zürich.

JEFFERY, L. H. (1990): The Local Scripts of Archaic Greece. A study of the Greek alphabet and its development from the eighth to the fifh centuries B.C. Revised edition with a supplement by A.W. Johnston. Clarendon Press, Oxford.

JOHNSTON, A. W. y PANDOLFINI, M. (2000): Le Iscrizioni. Gravisca. Scavi nel santuario greco, II-15. Edipuglia, Bari.

KNAPP, P. (1876): Nike in der Vasenmalerei. Fues, Tübingen.

LECLERC, M. C. (1997): “L'insoutenable légèreté de la victoire: Niké chez Homère et Hésiode", Revue des Etudes Grecques 110: 325-352.

LORRIO ALVARADO, A. (1988-89): “Cerámica gris a torno de la necrópolis de Medellín”, Zephyrus 4142: 283-314.

LLOMPART, J.; ORTA, E. M.; GARRIDO, J. P.; GONZÁLEZ DE CANALES, F. y SERRANO, L. (2010): "Discusión en torno a la lectura y soporte de una inscripción griega arcaica con dedicatoria a la diosa Hi/estia hallada en Huelva", Huelva en su

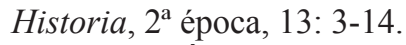

MANCEBO DÁVALOS, J. (1994): “Las cerámicas grises a torno orientalizantes de la Cuenca Baja del Guadalquivir", en J. M. Campos, J. A. Pérez y F. 
Gómez (eds.), Arqueología en el entorno del Bajo Guadiana, Actas del Encuentro Internacional del Bajo Guadiana (Huelva y Niebla, 25-27 de febrero de 1993): 351-373. Grupo de Investigación Arqueológica del Patrimonio del Suroeste, Huelva.

MARK, I. S. (1993): The Sanctuary of Athena Nike in Athens. Architectural Stages and Chronology. Hesperia Supplement 26. The American School of Classical Studies at Athens, Princeton.

MARK, I. S. (1979): Nike and the Cult of Athena Nike on the Athenian Acropolis. Doctoral Thesis, Institute of Fine Arts, New York University.

MURRAY, O. (1994): "Nestor's Cup and the Origins of the Greek Symposion”, en B. D'Agostino y D. Ridgway (eds.), APOIKIA. I più antici insediamenti greci in Occidente: Funzione e modi dell'organizzazione politica e sociale. Scritti in onore di G. Buchner. AIONArchStAnt. N.S. 1: 47-54.

OLMOS ROMERA, R. (1978): “La cerámica ática del Cabezo de San Pedro", en M. Belén Deamos, M. Fernández Miranda y J. P. Garrido Roiz, Los orígenes de Huelva. Excavaciones en los Cabezos de San Pedro y de La Esperanza. Huelva Arqueológica 3/1977, Apéndice 1: 377-393.

OLMOS ROMERA, R. (1987): “Comastas en Tartessos. En torno a la iconografía del vino y la danza simposíaca en la Península Ibérica”, en L. A. de Cuenca, E. Gangutia Elícegui, A. Bernabé Pajares y J. López Facal (coords.), Athlon. Satura Grammatica in honorem F. R. Adrados, vol. II: 683-696. Gredos, Madrid.

OLMOS, R. y CABRERA, P. (1980): "Un fragmento de Clitias en Huelva", Archivo Español de Arqueología 53: 5-14.
PETRIE, W. F. (1886): Naukratis I: 1884-1885. Trübner, London.

PLÁCIDO SUÁREZ, D. (2008): “Océano y sus hijos: la proyección espacial del mito”, en R. González Antón, F. López Pardo y V. Peña Romo (eds.), Los fenicios y el Atlántico, IV Coloquio del CEFYP: 31-37. Centro de Estudios Fenicios y Púnicos, Madrid.

RIDGWAY, B. S. (1986): "The Nike of Archermos and her attire", en J. Boardman y C. E. VaphopoulouRichardson (eds.), Chios. A conference at the Homereion in Chios 1984: 259-274. Clarendon Press, Oxford.

SCHERRER, P. (1983): "Das Weihgeschenk von Mikkiades und Archermos aus Delos", Jahreshefte des Österreichischen Archäologischen Institutes in Wien 54: 19-25.

SIKES, E. E. (1985) "Nike and Athena Nike", The Classical Review 9: 280-283.

SHEEDY, K. (1985): "The Delian Nike and the Search for Chian Sculpture", American Journal of Archaeology 89: 619-626.

SMITH, T.J. (2010): Komast Dancers in Archaic Greek Art. Oxford University Press, Oxford.

THOMPSON, J. A. K. (1920): "The religious background of the Prometheus Vinctus", Harvard Studies in Classical Philology 31: 1-37.

THÖNE, C. (1999): Ikonographische Studien zu Nike im 5. Jahrhundert v.Chr.: Untersuchungen zur Wirkungsweise und Wesenart. Verlag Archäologie und Geschichte, Heidelberg.

VON FRANZ, M. L. (1985): "Nike und die Gewässer der Styx", Eranos 54: 455-483.

FeCHA DE ENTRADA: 8-03-2010

FECHA DE ACEPTACIÓN: 16-11-2010

ISSN: 1133-4525 ISSN-e: 2255-3924 